\title{
Nociceptive Threshold and Physical Activity
}

\author{
Régis Guieu, Olivier Blin, Jean Pouget and Georges Serratrice
}

\begin{abstract}
Previous studies using subjective tools to measure pain have shown that muscle exercise can have analgesic effects in man. The nociceptive leg flexion reflex (or RIII reflex) is a useful objective tool for assessing human pain. In this study, the pain threshold was assessed using the nociceptive flexion reflex in six high-level athletes 1 ) at rest in comparison with 8 control subjects and 2) after exercise requiring the production of a 200-Watt force over a period of 20 minutes. The nociceptive flexion reflex threshold at rest was found to be spontaneously higher in the athletes than in the controls. Physical activity resulted in a significant increase $(+53 \%)$ in the threshold of the nociceptive reflex in the athletes. The role of stress-induced analgesia, the reduction in perceived intensity of stimuli during movement, and the release of opioids are discussed.
\end{abstract}

RÉSUMÉ: Seuil nociceptif et activité physique. Des études antérieures utilisant des méthodes subjectives de mesure du seuil nociceptif ont montré que ce dernier s'élevait lors d'un exercise physique. Or il est possible de mesurer de manière objective et reproductible le seuil douloureux grâce à l'étude du seuil d'apparition du réflexe nociceptif de flexion de la jambe (ou réflexe RIII), celui-ci étant corrélé au seuil douloureux subjectif. Ce réflexe est obtenu par stimulation électrique du nerf sural provoquant une réponse motrice dans les muscles de la face postérieure de la cuisse. A partir de cette technique objective d'évaluation, notre étude montre qu'un effort de 200 watts soutenu pendant 20 minutes par des sportifs entraînés provoque une élévation moyenne de plus de $50 \%$ du seuil nociceptif. Mais le résultat principal est que le seuil nociceptif mesuré au repos est significativement plus élevé chez les sportifs entraînés que chez les témoins.

Can. J. Neurol.Sci. 1992; 19: 69-7I

Traumatic lesions occurring during intense physical activity (for example marathon events) are often accompanied by little or no pain.'

Physical exercise also seems to increase the dental pain threshold in man. ${ }^{2}$ It has been reported that the dental pain threshold increased by $100 \%$ in patients producing a muscle force equivalent to 300 watts for 8 minutes. ${ }^{3}$ In the latter studies, pain was assessed using subjective methods involving questionnaires or visual analogue scales.

The nociceptive leg flexion reflex (RIII) provides a useful and objective tool for assessing human pain. It is correlated with the sensation of pain induced by electrical stimulation of the sural nerve at the ankle. ${ }^{4}$

The aim of our study, was to use the leg nociceptive flexion reflex: 1) to test objectively whether physical effort increases the nociceptive threshold in high-level athletes, and 2) to test the nociceptive threshold of high-level athletes at rest and to compare it with that of control subjects.

\section{Materials ANd Methods}

This study was conducted on 8 control subjects ( 7 men and 1 woman), with ages ranging from 22 to 27 years (mean 24), who had undergone no intensive sports training, and 6 high-level athletes ( 4 men and 2 women) between the ages of 18 and 27 (mean 22 years), all of whom regularly participated in national or international sporting events and underwent one or two intensive training sessions every day. All of the subjects are volunteers, who agreed to participate in this study after being informed about the experimental procedure as per the Helsinki charter.

An electrical stimulator (RACIA's Algometer REF 4) with variable intensity, pulse width and rate, was used. Electrical stimulation of the sural nerve was applied in the external retromalleolar gutter in successive series of 5 rectangular pulses with a duration of $1 \mathrm{~ms}$ (interval of $2 \mathrm{~ms}$ ). The stimulating electrodes were placed $2 \mathrm{~cm}$ apart. The resistance between the two skin electrodes was continuously monitored and varied between 1 and 3 kilo-ohms. Since the subjects' perspiration levels were liable to vary during the session, we used a steady-current stimulator with which the voltage was automatically adjusted at the stimulator terminals so that a constant current was delivered whatever the cutaneous resistance. Under these conditions, for the same given intensity, the current density area was the same at rest and after exercise. With this precaution, it was possible to leave the electrodes in place throughout the entire duration of the test. The reflex activity was recorded at the short head of the biceps femoris on the same side as the stimulation. Electrical stimuli of variable intensity were applied every 6 seconds in

From the Clinique des maladies neuromusculaire et de l'appareil locomoteur, Marseille, France

Received January 25, 1991. Accepted in final form June 4, 1991

Reprint requests to: R. Guieu, Clinique des maladies neuromusculaire et de l'appareil locomoteur, Chu Timone, Avenue de l'armée d'Afrique 13385 Marseille Cedex 5, France 
random order, six times at each intensity level. The intensity of the stimulation was varied in three ascending and descending series in order to determine the reflex threshold. The reflex responses were full-wave rectified, integrated and were analyzed over $150 \mathrm{msec}(50-200 \mathrm{msec}$ window) amplified with a band pass of $10-1500 \mathrm{~Hz}$, with a gain of 240 microvolts and an acquisition delay of $50 \mathrm{msec}$. The EMG responses were digitized at $200 \mathrm{~Hz}$. The reflex threshold was conventionally defined as the smallest stimulus intensity eliciting a probability of $100 \%$ for RIII motor responses. To be accepted as a flexion nociceptive RIII, the recorded reflexes had to be polyphasic in shape with an onset latency exceeding $80 \mathrm{msec}$. These responses were associated with a subjective sensation of "pricking" pain at the stimulated site.

Athletes seated on an ergometric bicycle (Ketker fitness trademark) in a room at constant temperature (24 degrees Celcius) were asked to furnish a regular effort at 70 cycles $/ \mathrm{min}$, developing a force of 200 watts, amounting to roughly $50 \%$ of their maximum capacity, for 20 minutes. The subjects' heart rate and blood pressure were measured at rest (T0), after 10 minutes of exercise, and just before the end of the exercise (T20).

The nociceptive threshold was measured at rest and just after the end of the exercise in the athletes, and only at rest in the control subjects. The tests were carried out between 5 and 6 p.m.

Statistical analysis was performed using non parametric tests. The Mann-Whitney test was used to compare athletes with controls regarding their ages and nociceptive flexion reflex threshold. The Wilcoxon matched paired sign-rank test was used to compare pulse rate, blood pressure and nociceptive threshold before and after exercise in the athletes.

\section{RESULTS}

The ages of the controls and athletes showed no statistical differences $(U=13.5, p=0.06)$. The athletes' heart rates and blood pressures increased as a function of time during the physical activity. The comparison between T0 and T20 showed a significant increase in the heart rate (from $55 \pm 7$ to $109 \pm 10$ beats $/ \mathrm{min}, \mathrm{T}=0, \mathrm{p}<0.05$ ) and systolic blood pressure (from $120 \pm 12$ to $145 \pm 10 \mathrm{mmHg}, \mathrm{T}=0, \mathrm{p}<0.05$ ).

The 200-watt physical activity led to a significant increase in the nociceptive threshold in the trained subjects $(T=0, p<.05)$, mean increase $>55 \%$ (Table 1). The athletes' nociceptive threshold at rest was significantly higher than that of control subjects one $(\mathrm{U}=7, \mathrm{p}<.05)$.

\section{Comments}

Our study demonstrates that physical activity enhances the leg nociceptive flexion reflex threshold and therefore increases the nociceptive threshold. These data confirm previous results obtained using more subjective methods. $2,3,5$

The nociceptive flexion reflex is a polysynaptic reflex ${ }^{6}$ which is subject to supraspinal modulation. ${ }^{7}$ Intellectual concentration during mental calculation for instance, reduces pain sensitivity and increases the nociceptive flexion reflex threshold. ${ }^{4}$ Physical exercise is known to activate stress mechanisms. ${ }^{8}$ Hence, intense concentration and stress-induced analgesia ${ }^{9}$ may together explain the nociceptive threshold increase observed here during physical exercise.
Table 1: Leg Flexion Nociceptive Reflex Thresholds in 6 Athletes At Rest and After 20 Months of Exercise At 200 Watt Effort, and in 8 Control Subjects at Rest.

\begin{tabular}{clll}
\hline \hline Subject & At Rest & Athletes & $\begin{array}{c}\text { Controls } \\
\text { At Rest }\end{array}$ \\
\hline 1 & $9.5+/-0.3^{*}$ & $13.5+/-0.8$ & $9+/-0.1$ \\
2 & $10.5+/-0.6$ & $12+/-0.3$ & $7+/-0.3$ \\
3 & $14.5+/-0.9$ & $16.5+/-0.8$ & $10+/-0.4$ \\
4 & $23.5+/-0.6$ & $>50$ & $12+/-0.6$ \\
5 & $25+/-0.3$ & $41+/-1$ & $10+/-0.2$ \\
6 & $22+/-0.9$ & $38+/-0.9$ & $9+/-0.3$ \\
7 & & & $7.5+/-0.1$ \\
8 & & & $15+/-0.5$ \\
Mean & 17.5 & 28.5 & 9.93 \\
SD & 6.8 & 16 & 2.57 \\
\hline
\end{tabular}

*mean $\pm \mathrm{SD}$. Threshold values are expressed in milliamperes.

Another possible explanation for the analgesic effects observed during physical effort is that they may simply be induced by movement: even when moving subjects were making no particular effort, the perceived intensity of nociceptive stimuli was induced. ${ }^{10}$ These analgesic effects were moderate, however, and did not persist after the movement.

Intense physical activity increases not only the nociceptive threshold but also pituitary hormone production (adrenocorticotrophin hormone, prolactin, growth hormone $(\mathrm{GH})$ ) and cortisol release. ${ }^{2}$ Since the GH antagonist cyproheptadine ${ }^{11}$ does not prevent the nociceptive threshold from increasing the physical activity, the causal relationship between the $\mathrm{GH}$ release and the increase of the nociceptive threshold remains doubtful. Since dexamethasone, which reduced adrenocorticotrophin release, attenuates exercise-induced-dental analgesia in $\operatorname{man}^{12}$ and adrenal corticotrophin hormone is increased in exercise, it may be suggested that adrenocorticotrophin hormone release plays a role in the exercise induced analgesia.

Some authors have stated that endogeneous opioid release plays only a minor role, if any, in the analgesia induced by physical activity. ${ }^{13}$ Naloxone, a opioid antagonist, does not prevent the nociceptive threshold from increasing with physical activity. ${ }^{5}$ However, the overall ability of naloxone to reverse the effects of opioids is a controversial issue. ${ }^{14,15}$ In some cases, the injection of naloxone reverses the analgesic effects of exercise, in the event of ischemia induced pain. ${ }^{16}$ In these cases, the effort was intense and prolonged, resembling that required in marathon racing; this type of effort is likely to produce endorphin release. ${ }^{17}$

The nociceptive threshold at rest was found here to be spontaneously higher in the athletes than in the controls. This result seems to support the hypothesis that chronic neuropeptide secretion occurs in high-level athletes undergoing intensive daily training. This hypothesis requires further experiments.

\section{ACKNOWLEDGEMENT}

English revision by Dr. Jessica Blanc. 


\section{REFERENCES}

1. Black J, Chesler GB, Starmer GA. The painlessness of the long distance runner. Med J Aust 1970; 2: 522-523.

2. Pertovaara A, Huopaniemi T, Virtanen A, et al. The influence of exercise on dental pain thresholds and the release of stress hormones. Physiol Behav 1984; 3: 923-926.

3. Kemppainen P, Pertovaara A, Huopaniemi T, et al. Modification of dental pain and cutaneous thermal sensitivity by physical exercise in man. Brain Res 1985; 36: 33-40.

4. Willer JC. Nociceptive flexion reflex as a tool for pain research in man. In: Desmedt JE, ed. Advances in Neurology, Raven Press: New York 1983; 39: 809-827.

5. Olausson B, Eriksson E, Ellmaker L, et al. Effects of naloxone on dental pain threshold following muscle exercise and low frequency transcutaneous electrical nerve stimulation: a comparative study in man. Acta Physiol Scand 1986; 126: 299-305.

6. Hugon M. Réflexes polysynaptiques et réflexes monosynaptiques évoqués dans le muscle biceps fémoris capitis brévis chez l'homme normal. Rev Neurol 1969; 120: 492-494.

7. Bathien N. Réflexes spinaux chez l'homme et niveaux d'attention. Electroencephalogr Clin Neurophysiol 1971; 30: 32-37.

8. Kuoppasalmi K. Effects of exercise stress on human plasma hormone levels. MD Thesis, 1981, University of Helsinki.

9. Lewis JW, Terman GW, Shavit Y, et al. Neural, neurochemical, and hormonal basis of stress-induced analgesia. In: Kruger $\mathrm{L}$ and
Liebeskind JC, eds. Neural mechanism of pain. Raven Press: New York 1984: 277-288.

10. Milne RJ, Aniss AM, Gandevia SC. Reduction in perceived intensity of cutaneous stimuli during movement: a quantitative study. Exp Brain Res 1988; 70: 569-576.

11. Kemppainen P, Pertovaara A, Huopaniemi T, et al. Elevation of dental pain threshold induced in man by physical exercise is not reversed by cyproheptadine mediated suppression of growth hormone release. Neurosci Lett 1986; 70: 388-392.

12. Kemppainen $P$, Paalasmaa $P$, Pertovaara A, et al. Dexamethasone attenuates exercise-induced dental analgesia in man. Brain Res 1990; 519: 329-332.

13. Pertovaara A, Kemppainen P, Huopaniemi T, et al. Pain and stress: correlation of stress hormone release to pain modulation in man. Ann Clin Res 1987; 19: 83-86.

14. Gilman MA, Lichigjeld M. Naloxone analgesia: an update. Intern J Neurosci 1989; 48: 321-324.

15. Sawynok J, Pinsky C, Labella FS. Minireview of the specificity of naloxone as an opiate antagonist. Life Sci 1979; 25: 1621-1632.

16. Janal MN, Colt EW, Clark WC, et al. Pain sensitivity, mood and plasma endocrine levels in man following long-distance running: effect of naloxone. Pain 1984; 19: 13-25.

17. Colt EWD, Wardlaw SL, Frantz AG. The effect of running on plasma endorphin. Life Sci 1981; 28: 1637-1640. 